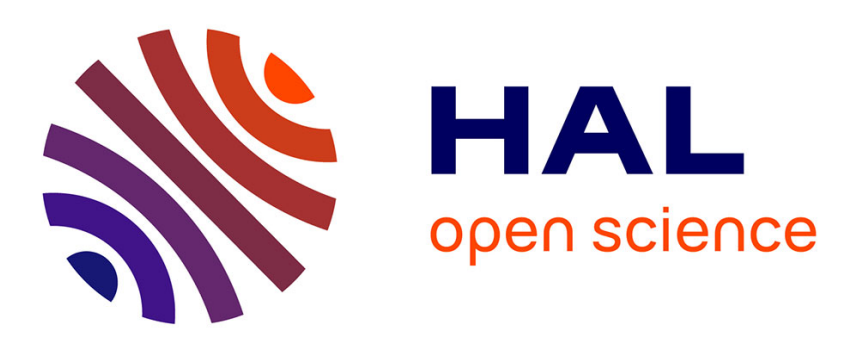

\title{
A probabilistic model for the high cycle fatigue behaviour of cast aluminium alloys subject to complex loads
}

\author{
Imade Koutiri, Daniel Bellett, Franck Morel, Etienne Pessard
}

\section{To cite this version:}

Imade Koutiri, Daniel Bellett, Franck Morel, Etienne Pessard. A probabilistic model for the high cycle fatigue behaviour of cast aluminium alloys subject to complex loads. International Journal of Fatigue, 2013, 47, pp.137-147. 10.1016/j.ijfatigue.2012.08.004 . hal-00821800

\section{HAL Id: hal-00821800 https://hal.science/hal-00821800}

Submitted on 13 May 2013

HAL is a multi-disciplinary open access archive for the deposit and dissemination of scientific research documents, whether they are published or not. The documents may come from teaching and research institutions in France or abroad, or from public or private research centers.
L'archive ouverte pluridisciplinaire HAL, est destinée au dépôt et à la diffusion de documents scientifiques de niveau recherche, publiés ou non, émanant des établissements d'enseignement et de recherche français ou étrangers, des laboratoires publics ou privés. 


\title{
A probabilistic model for the high cycle fatigue behaviour of cast aluminium alloys subject to complex loads
}

\author{
Imade Koutiri, Daniel Bellett $\mathbf{\Delta}, \boldsymbol{\nabla}$, Franck Morel, Etienne Pessard
}

Arts et Métiers ParisTech, CER Angers, Laboratoire LAMPA, 2 Bd du Ronceray, 49035 Angers Cedex 1, France

\section{Abstract}

This article is dedicated to the high cycle fatigue behaviour of cast hypo-eutectic $\mathrm{Al}-\mathrm{Si}$ alloys and in particular the AISi7Cu05Mg03 alloy. In a vast experimental campaign undertaken to investigate the fatigue damage mechanisms operating in this alloy, subject to complex loading conditions, it was shown that two different coexisting fatigue damage mechanisms occur in this materials, depending on the presence of different microstructural heterogeneities (i.e. micro-shrinkage pores, Si particles, Ferich intermetallic phases, DAS of the Al-matrix, etc.). In order to take into account both of these damage mechanisms, a probabilistic approach using the weakest link concept is introduced to model the competition between the two mechanisms. This approach leads naturally to a probabilistic Kitagawa type diagram, which explains the relationship between the fatigue behaviour of the material and the different casting processes or post-treatments (e.g. gravity casting and HIP).

It is shown that the sensitivity to the different loading modes (i.e. uniaxial with and without mean stress, torsion and equibiaxial tension) depends on the microstructural heterogeneities responsible for crack initiation. For a porosity-free alloy, the predictions are very good for combined tension-torsion loading modes. When pores are present and control the fatigue strength, the predictions are very satisfactory for the uniaxial loads with different R-ratios and slightly conservative for multiaxial loads (i.e. torsion and equibiaxial tension). Never-the-less, they are much better than the predictions of the Dang Van criterion [1].

\section{Highlights}

- High cycle fatigue modelling of AISi7Cu05Mg03 for complex loading conditions. - Modelling of two coexisting fatigue damage mechanisms. - A probabilistic approach is proposed to model the competition between these mechanisms. - The approach leads naturally to a probabilistic Kitagawa type diagram.

\section{Keywords}

High cycle fatigue; AlSi7Cu05Mg03-T7; Multiaxial loads; Probabilistic model; Fatigue damage mechanisms 


\section{Introduction}

The fatigue design of mechanical components subjected to complex loading conditions, including high mean stress and a high degree of stress triaxiality (or a high hydrostatic stress), is still the subject of much scientific debate. Most often, the fatigue damage mechanisms as well as the fatigue strength are completely unknown for such complex loading conditions. Moreover, existing fatigue models have difficulties predicting the mechanical response under these loading conditions and the fatigue data necessary to identify the criterion parameters are practically non-existent.

An example of this type of problem is the fatigue design of cast aluminium diesel engine cylinder heads used in the automotive industry. These gravity sand cast components have a very complicated geometry but are essential to the correct operation of the engine. The combination of the manufacturing process, the assembly loads and the in-service conditions result in fatigue critical zones that are characterised by a cyclic stress state with a high degree of biaxiality and very high mean stresses. The object of this work is to develop an appropriate high cycle fatigue criterion for this application.

It has been demonstrated [2] and [3] that the degree of microstructural heterogeneity of metallic materials is directly responsible for the sensitivity of the material to the loading mode and path in high cycle fatigue. In other words, good knowledge of the microstructure is crucial to establishing reliable fatigue strength predictions under complex loading conditions. For the cast aluminium material investigated here (AISi7Cu05Mg03) this is a crucial point. The microstructural heterogeneities present in this type of material include: micro-shrinkage porosity, gas porosity, oxides, intermetallic phases, eutectic silicon particles and intermetallic phases. Furthermore, the casting process used to fabricate the components has a very strong influence on the type of heterogeneities present.

Much research has been reported in the scientific literature concerning the fatigue behaviour of cast aluminium-silicon alloys [4], [5], [6], [7], [8], [9], [10], [11], [12], [13], [14], [15], [16], [17] and [18]. This body of work is generally related to uniaxial loads at low R-ratios (i.e. $R=-1$ or 0.1 ). This research makes it clear that the different microstructural heterogeneities present in the material have a detrimental effect on the average fatigue life and increase the scatter in the fatigue data. Also, it can be noted that different fatigue damage mechanism occur in these materials depending on which microstuctural heterogeneities are present.

It is generally accepted that when micro-shrinkage pores are present they play a fundamental role in controlling the fatigue behaviour. Their size, position, distribution, etc., have a large impact on the fatigue resistance of the material. This relationship between the fatigue behaviour and the degree of porosity present in the microstructure has been well documented in the literature [14] and [15]. However, when specific casting processes or post-casting treatments, such as HIP (Hot Isostatic Pressing), are used to obtain a microstructure in which the porosity is practically eliminated, crack initiation occurs at other microstructural heterogeneities, such as oxide inclusions, eutectic silicon particles and intermetallic phases [4], [9],,$\underline{[10]}$ and [11]. 
In the experimental part of this work, 1 numerous fatigue damage observations have been undertaken using specimens extracted from gravity sand cast cylinder heads produced by the French automotive manufacturer PSA (Peugeot-Citroën). These observations show that the fatigue crack, resulting in final failure of the specimens, almost always initiates at micro-shrinkage pores. However, it is very important to note, that in the same specimens, micro-cracks are also observed to initiate at silicon particles in the eutectic zones or at intermetallic phases. For the material and loading conditions in question, this type of damage is not generally responsible for the final failure of the specimen, but it does co-exist with the damage that occurs at the shrinkage pores.

As part of the experimental campaign, various cyclic loading conditions were investigated (i.e. uniaxial loads with different mean values, torsional loads, and a loading condition resulting in an equibiaxial stress state). The experimentally determined fatigue strengths at $2 \times 10^{6} \mathrm{cycles}$, are summarised in Table 1. It was also shown, that the damage mechanisms occurring in plane bending and equibiaxial tension are very similar, except there is no preferential crack growth direction in the latter case. It has also been demonstrated that although the elastic shakedown concept is valid at the macroscopic scale, Dang Van type criteria [1],[19] and [20] are unable to explain the experimentally observed tendencies for the different loading conditions applied to this cast aluminium alloy.

\begin{tabular}{|c|c|c|c|}
\hline бmean $(\mathrm{MPa})$ & бamp (MPa) & Load ratio & Standard deviation (MPa) \\
\hline \multicolumn{4}{|l|}{ Plane bending } \\
\hline 0 & 83 & -1 & 18 \\
\hline 77 & 63 & 0.1 & - \\
\hline 196 & 45 & 0.62 & - \\
\hline 251 & 15 & 0.88 & - \\
\hline 284 & 12 & 0.92 & - \\
\hline \multicolumn{4}{|l|}{ Uniaxial tension } \\
\hline 83 & 51 & 0.25 & - \\
\hline 172 & 26 & 0.73 & - \\
\hline \multicolumn{4}{|l|}{ Torsion } \\
\hline$\tau_{\text {mean }}(\mathrm{MPa})$ & $\tau_{a m p}(\mathrm{MPa})$ & Load ratio & Standard deviation (MPa) \\
\hline 0 & 92 & -1 & 14 \\
\hline \multicolumn{4}{|c|}{ Axisymmetrical bending $\sigma_{11}(t)=\sigma_{22}(t)$} \\
\hline$\sigma_{11}$ mean $=\sigma_{22, \text { mean }}(\mathrm{MPa})$ & $\sigma_{11, a m p}=\sigma_{11, a m p}(\mathrm{MPa})$ & Load ratio & Standard deviation (MPa) \\
\hline 77 & 63 & 0.1 & - \\
\hline
\end{tabular}

From a high cycle fatigue modelling point of view, many approaches have been proposed in the literature to take into account the fatigue behaviour of cast aluminium alloys. A review of the relevant literature leads to the following conclusions:

-When present, shrinkage pores and their size distribution are generally considered to be the principal factors influencing the fatigue behaviour. High cycle fatigue models proposed to predict the fatigue behaviour of cast aluminium alloys are very often based on fracture mechanics 
concepts, whereby these defects are treated as being equivalent to cracks with an initial length [13], [15] and [16].

- Effective stress intensity factors, $\Delta K$ Keff are often used to take into account the means stress effect, via the phenomenon of crack closure. For the material investigated here, the value of the effective stress intensity threshold cited in the literature is between 0.6 and 1.5 MPa $\sqrt{\mathrm{m}}$ [13], [15], [16] and [17].

- For alloys elaborated using a HIP process (in which the porosity is practically eliminated) certain authors consider that the fatigue damage process is controlled by localised cyclic plasticity occurring due to other microstructural heterogeneities (i.e. silicon particles in the eutectic zones, intermetallic phases or oxides) [6], [4] and [5]. The concept of elastic shakedown at the mesoscopic scale is then sometimes used to evaluate the fatigue life, as per certain multiaxial fatigue criteria like the Dang Van[1], [19] and [20], Papadopoulos [21] or the Huyen and Morel [2] and [3] criteria.

- The total fatigue life is often divided into at least two parts, the first is associated with crack initiation and the second is due to crack propagation. Special considerations for the propagation of short cracks are also often included in the criteria [5] and [18].

There are however certain aspects that have had very little attention from the scientific community. The most notable is the fact that most criteria proposed in the literature are typically only based on uniaxial loading conditions. Multiaxial loads, such as torsional loads, combined tension/torsion and biaxial tensile loads are rarely discussed.

In the following a new fatigue model is proposed using a probabilistic framework which is able to take into account the two experimentally observed co-existing fatigue damage mechanisms. It is shown that this criterion is able to take into account certain effects, in particular those due to the loading mode and the mean stress.

\section{A new probabilistic high cycle multiaxial fatigue model for cast}

\section{aluminium alloys}

\subsection{Modelling strategy to account for the effects of different microstructural heterogeneities}

The adopted modelling approach was first proposed by Pessard et al. [22] to reflect experimental observations highlighting a state of competition between two very different fatigue crack initiation mechanisms in a bainitic steel [22], [23] and [24]. These authors showed that fatigue anisotropy could be explained by a change in the fatigue damage mechanism. They observed that when the fibering direction of the hot rolled material was parallel with the loading axis, fatigue crack initiation occurred in the bainitic material matrix on planes of maximum shear stress. That is, cracks were initiated via 
localised plasticity occurring at the mesoscopic scale. This first mechanism, was modelled by a twoscale mulitaxial fatigue model, used to estimate the elastic shakedown state at the mesoscopic scale. These authors also observed a second damage mechanism, which became more active when the specimen fibering direction was orientated perpendicular to the loading axis. In this case, fatigue cracks initiated at clusters of elongated MnS inclusions. This second mechanism was modelled using linear elastic fracture mechanics concepts, in which these pre-existing microstructural heterogeneities were considered to be pre-existing cracks.

From the probability of failure in the material matrix, referred to as $P_{F_{1}}$, and the probability of a crack propagating from elongated MnS inclusion clusters, referred to as $P_{F_{2}}$, the weakest link hypothesis is used to obtain the overall probability of survival of the component:

$$
1-P_{F}=\left(1-P_{F_{1}}\right)\left(1-P_{F_{2}}\right)
$$

In the following this approach is applied to cast aluminium alloys in which two distinct fatigue damage mechanisms have also been observed. The Huyen and Morel [2] and [3] criterion is used to estimate the probability of crack initiation in the material matrix. That is, crack initiation due to localised plasticity typically occurring in the eutectic zone of the material at either silicon particles or intermetallic phases. A linear elastic fracture mechanics approach is then used to estimate the probability of failure from the shrinkage pores.

The first term $\left(1-P_{F_{1}}\right)$ of Eq. (1) is used to reflect the effects of micro-plasticity for the case where the material is defect free. The second term $\left(1-P F_{2}\right)$ takes into account influence of the porosity on the fatigue behaviour. Eq. (1) is therefore capable of simultaneously take into account the effect of the microstructure and the loading mode.

\subsection{Multiaxial fatigue behaviour of porosity-free cast aluminium alloys}

\subsubsection{Experimental behaviour under different loading modes}

The aluminium alloy AISi7Cu05Mg03 investigated in the experimental part of this work (See Footnote 1), was gravity sand cast. For this combination of material and forming process the porosity has a large influence on the fatigue behaviour.

In order to establish a multiaxial fatigue model, capable of reflecting the crack initiation mechanisms that occur in an alloy without porosity, fatigue data from the literature is used. Data for tensile and combined tension/torsion loading modes, of the A356-T6 alloy are taken from the work of Fan et al. [6]. The material studied by these authors was subject to a HIP treatment and by consequence contains a very low porosity volume fraction $(<0.01 \%)$. To compare the fatigue results obtained for a load ratio of $R=-1$, the von Mises effective strain amplitude, defined by Eq. (2), was used by the authors.

$$
\varepsilon_{e f f}^{a}=\sqrt{\left(\frac{\Delta \varepsilon}{2}\right)^{2}+\left(\frac{1}{\sqrt{3}} \frac{\Delta \gamma}{2}\right)^{2}}
$$


where $\Delta \varepsilon$ and $\Delta y$ are the axial strain range and the engineering shear strain range in an axial-torsional test of a thin-walled tubular specimen.

Fully reversed torsion tests, fully reversed uniaxial tests, and combined tension-torsion tests were done for different strain levels $\left(\varepsilon_{\text {eff }}^{a}=0.3 \%, 0.2 \%\right.$ and $\left.0.1 \%\right)$. The authors highlight the low scatter in the results, due to the low level of porosity, thanks to the HIP treatment. For high effective strain amplitudes, a difference between the three loading modes was noted. This is not the case for low strain amplitudes, for which only a small difference is observed. In order to facilitate its use in the proposed probabilistic multiaxial fatigue model, this data [6] has been transformed to stress-life values using the typical linear elastic constitutive equation, for the three loading modes.

For a fatigue life of $2 \times 10^{6}$ cycles, the fully reversed tensile and torsional fatigue strengths are approximately $s_{-1}=112 \mathrm{MPa}$ and $t_{-1}=75 \mathrm{MPa}$. For the fully reversed combined tension-torsion loading mode the fatigue strength is given by $s_{-1}=76 \mathrm{MPa}$ and $t_{-1}=53 \mathrm{MPa}$.

With respect to the uniaxial tensile fatigue strength and the experimental data reported in Table 1 , these results from the literature are logical, as the presence of porosity has a detrimental effect. The fatigue strength is $112 \mathrm{MPa}$ for the HIP treated material [6] and $83 \mathrm{MPa}$ for the sand cast material.

However, a surprising result concerns the ratio of the uniaxial tensile (or plane bending) fatigue limit to the torsional fatigue limit. For the sand cast alloy extracted from the cylinder heads, the plane bending fatigue strength and the torsional fatigue strength are very similar. This is in contrast to the alloy treated using the HIP process [6], for which a greater difference between these two fatigue limits is observed. Table 2summarises this data. It can be seen that the ratio of the torsional fatigue strength $t$ ${ }_{1}$ to the plane bending $f_{-1}$ (or tensile $s_{-1}$ ) fatigue strength goes from 1.1 to 0.71 if the porosity is eliminated from the material. The latter is typical of the ratio often observed for steels.

Table 2. Experimental values for the fatigue strength of the cast aluminium alloys.

\begin{tabular}{l|l|l|l}
$\begin{array}{l}\text { Fatigue strength at } \\
2 \times 10^{6} \text { cycles }(R=-1)\end{array}$ & $\begin{array}{l}\text { Plane bending or traction- } \\
\text { compression } s_{-1} \text { or } f_{-1}(\mathrm{MPa})\end{array}$ & $\begin{array}{l}\text { Fully reversed } \\
\text { torsiont } t_{-1}(\mathrm{MPa})\end{array}$ & $\begin{array}{l}\text { Fatigue strength } \\
\text { ratio }\end{array}$ \\
$\begin{array}{l}\text { AlSi7Cu05Mg03-T7 } \\
\text { Sand cast (PSA) }\end{array}$ & 83 & 92 & 1.1 \\
\hline $\begin{array}{l}s_{-1} \\
\text { A356-T6 (HIP treatment) }\end{array}$ & 112 & 75 & 0.7 \\
\hline 6$]$ & & &
\end{tabular}

The comparison shown in Table 2 clearly highlights that the porosity has much greater influence on uniaxial loads than on torsional loading modes.

\subsubsection{Crack initiation modelling}

The preceding discussion highlights the fact that a HIP treatment results in fatigue crack initiation that generally occur at either the silicon particles in the eutectic zones or at intermetallic phases. Fig. 1a shows an example of this type of fatigue damage and Fig. 1b schematically presents the important features of the micro-plasticity approach used to model fatigue crack initiation in a porosity-free material. As per the Huyen and Morel criterion [2] and [3] it is assumed here that the crack initiation 
zone can be modelled using an elastoplastic inclusion surrounded by an elastic matrix (see Fig. 1b). This is very similar to the "micro-cell" model proposed by [4].

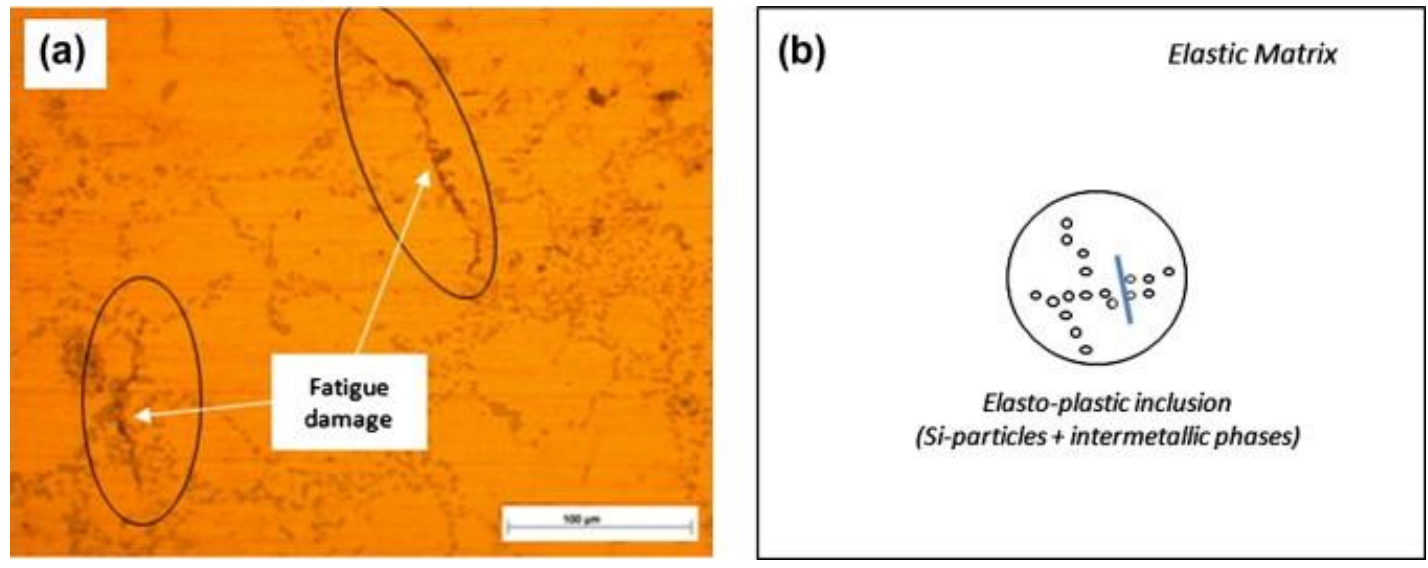

Fig. 1. (a) An SEM image showing fatigue damage in the material matrix and (b) a schematic illustration of the micro-mechanical model.

In the model developed by Pessard and Morel [23], [24] and [22], it is assumed that when a condition of plastic shakedown is achieved in one (or more) grains, fatigue failure is inevitable. To calculate the global probability of failure of the structure, it is sufficient to sum the failure probabilities for each of the grains contained in the loaded volume. By introducing a Weibull distribution [25], [26], [27], [28] and [29] to describe the elastic shakedown threshold at the mesoscopic scale and by using the weakest link hypothesis to consider all possible directions and the total stressed volume, the failure probability is described by:

$$
P_{F 1}=1
$$

$$
-\exp \left[-\frac{1}{V_{01}} \int_{V}\left\{\int_{\theta=0}^{\pi} \int_{\phi=0}^{2 \pi} \int_{\psi=0}^{2 \pi}\left(\frac{T_{a}(\theta, \phi, \psi)}{T_{01}}\right)^{m_{1}} \sin \theta d \theta d \psi d \phi\right\} d V\right]
$$

where $T a$ is the amplitude of the macroscopic resolved shear stress acting on a slip system. The spherical coordinates $(\theta, \phi)$ are used to describe the slip plane normal vector $\vec{n}$ and a third angle, $\psi$, is used to define the shear direction in the plane. $T_{01}$ is the scale factor of the Weibull distribution, $m_{1}$ is the Weibull exponent and $V_{01}$ is a reference volume.

It is generally accepted that both the mean and the amplitude of the stress, normal to the slip plane, have an influence on crack initiation. In order to take into account both of these loading parameters, in terms of crack initiation, the following scale factor, $T_{01}$, is used:

$$
T_{01}(\phi, \theta, \psi)=T_{01}^{\prime} \frac{1-\gamma \sigma_{m}(\phi, \theta)}{1+\alpha \frac{\sigma_{a}(\phi, \theta)}{T_{a}(\phi, \theta, \psi)}}
$$

where $\sigma_{m}(\phi, \theta)$ and $\sigma_{a}(\phi, \theta)$ are the mean and the amplitude of the normal stress on the slip plane. $\gamma$ and $\alpha$ are the normal stress sensitivity coefficients. The ratio $\frac{\sigma_{a}(\phi, \theta)}{T_{a}(\phi, \theta, \psi)}$ is used to define the degree of triaxiality and has the effect of reducing the scale factor.

In order to simplify the notation, the parameter $I m_{1}$ is introduced and is given by:

$$
I_{m 1}=\int_{\theta=0}^{\pi} \int_{\phi=0}^{2 \pi} \int_{\psi=0}^{2 \pi}\left(\frac{\chi_{a}(\theta, \phi, \psi)}{\left(1-\gamma \sigma_{m}(\theta, \phi)\right) X_{a}}\right)^{m_{1}} \sin \theta d \theta d \phi d \psi
$$


where $X_{a}(\theta, \phi, \psi)=T_{a}(\theta, \phi, \psi)+\alpha \sigma_{a}(\theta, \phi)$ and $X_{a}=\max \theta, \phi, \psi\left\{X_{a}(\theta, \phi, \psi)\right\}$. The expression for the total probability of failure of the structure then becomes:

$$
P_{F 1}=1-\exp \left[-\frac{1}{V_{01}} \int_{V} \frac{X_{a}^{m_{1}} I_{m 1}}{T_{01}^{\prime m_{1}}} d V\right]
$$

For multiaxial loading conditions, it has been shown that this model is capable of accurately predicting certain effects relative to the loading path. Particularly for combined tension-torsion loads and biaxial tensile loads. The effects of out-of-phase loads and different loading frequencies are also correctly accounted for by this criterion [3].

\subsection{Crack growth from shrinkage pores}

\subsubsection{The crack propagation threshold distribution and the related failure probability}

Observation of the fatigue damage mechanisms that occur in the material extracted from cylinder heads cast by PSA (Peugeot-Citroën), have clearly shown that the shrinkage pores play a major role (see Fig. 2). Pessard and co-workers [23], [24] and [22] have shown that the fatigue criterion presented in the previous section is not appropriate to model the macroscopic fatigue behaviour of materials with defects and that it is preferable to use fracture mechanics concepts within a probabilistic framework. Consequently, the principal hypotheses used in the following are:

- Under the action of cyclic loads and for load levels close to the fatigue limit, micro-cracks initiate rapidly at shrinkage pores, present within the material, and have the same approximate dimensions as the pores. The fatigue problem then becomes one of crack propagation (or non-propagation).

- The opening mode (Mode I) is assumed to be the dominate crack propagation driving force.

- In order to take into account the effect of crack closure, the values of stress intensity are assumed to be a function of the applied load ratio.

- As an initial approximation, the effect of the pore geometry is neglected. The pores will be modelled as being semi-circular, embedded, surface cracks.

- The short crack problem is intrinsically taken into account via the use of the probabilistic framework presented below, which combines the two fatigue damage mechanisms. That is, when the crack or defect size is small, the dominate fatigue damage is due to localised cyclic plasticity (i.e. mechanism 1). 

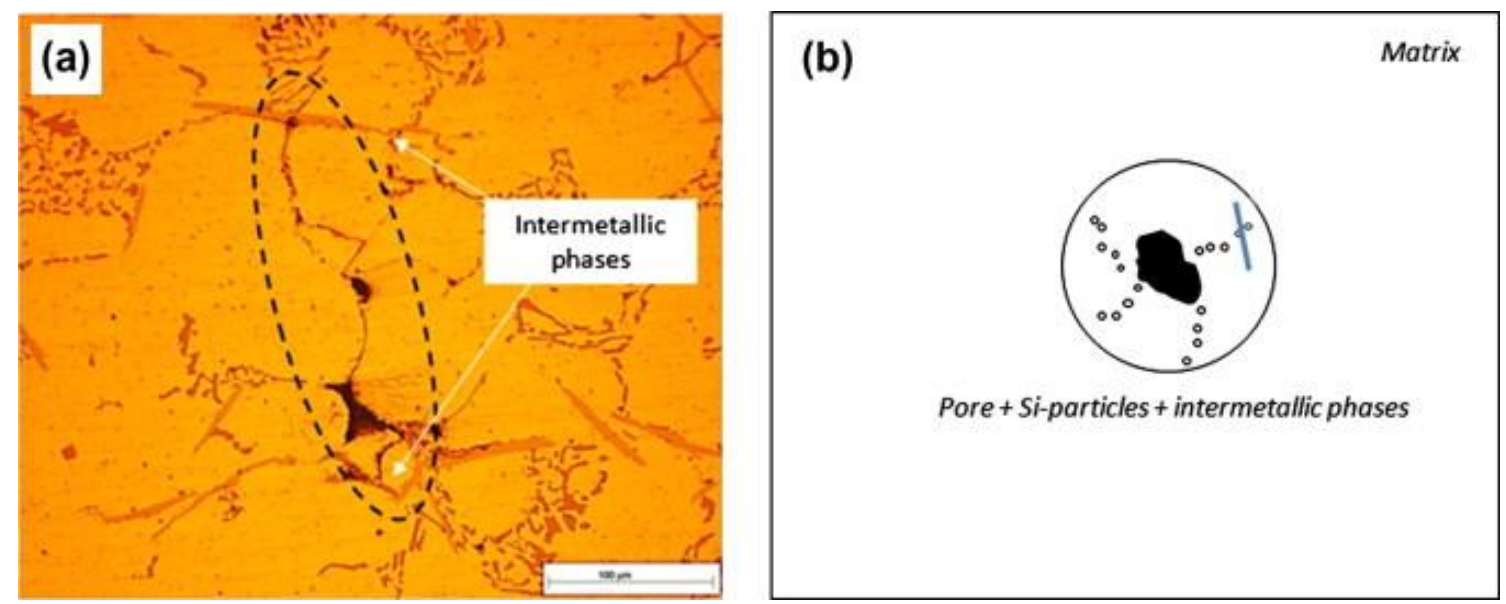

Fig. 2. (a) Crack growth from a micro-shrinkage pore. Note that the presence of intermetallic phases acting as microstructural barriers to crack propagation and (b) a schematic representation of the micro-mechanical model.

The classical approach to predict fatigue behaviour using linear elastic fracture mechanics is given by the condition:

\section{(7) $\quad \Delta K<\Delta K$ th}

That is, a crack will not propagate if its stress intensity range, $\Delta K$, is less than the crack propagation threshold, $\Delta K$ th.

Certain authors [22], [25] and [26] have discussed the possibility of linking the defect size distribution to the experimentally observed scatter in the fatigue strength. This option is not chosen here, as the work by [22] has shown that the link between these two distributions cannot always be made. It is certain that defect size has an influence on the fatigue strength but it is not only these microstructural heterogeneities that have an influence on the conditions of crack propagation. In the following, the random character of the propagation threshold is introduced via a Weibull distribution [28] and [29] that takes into account both the variation in the pore size and the variations in the microstructure around the pores. That is, the presence of silicon particles, or intermetallic phases and the orientation of the $\alpha$-Al phase. These heterogeneities can be more or less favourable to the propagation of cracks that initiate at pores.

As per the previous approach based on microplasticity, all potential cracks are taken into account via the calculation of $\Delta K(\theta, \phi)$ for each possible propagation plane, defined by the angles $(\theta, \phi)$.

The total probability of failure for the complete structure can be obtained by applying the weakest link theory over all the potential crack planes and over the total stressed volume. This then leads to:

$$
P_{F 2}=1-\exp \left[-\frac{1}{V_{02}} \int_{V}\left\{\int_{\theta=0}^{\pi} \int_{\phi=0}^{2 \pi}\left(\frac{\Delta K(\theta, \phi)}{\Delta K_{t h 02}}\right)^{m_{2}} \sin \theta d \theta d \phi\right\} d V\right]
$$

where the Weibull exponent, $m_{2}$, governs the scatter and $\Delta K$ tho2 is the scale factor associated with the second fatigue damage mechanism. The stress intensity factor associated with plane $(\theta, \phi)$ can be written in terms of a crack or defect size, $a$, and the normal stress applied to the plane, $\Delta \sigma(\theta, \phi)$ :

(9) $\Delta K(\theta, \phi)=\Delta \sigma(\theta, \phi) \beta \sqrt{\pi a}$ 
By using this expression the total probability of failure of the total structure is:

$$
P_{F 2}=1
$$

$$
-\exp \left[-\frac{1}{V_{02}} \int_{V}\left\{\int_{\theta=0}^{\pi} \int_{\phi=0}^{2 \pi}\left(\frac{\Delta \sigma(\theta, \phi) \beta \sqrt{\pi a}}{\Delta K_{t h 02}}\right)^{m_{2}} \sin \theta d \theta d \phi\right\} d V\right]
$$

It is possible to simplify the expression for $P F_{2}$ by introducing the factor $J m_{2}$, which is defined by:

$$
J_{m 2}=\int_{\theta=0}^{\pi} \int_{\phi=0}^{2 \pi}\left(\frac{\Delta \sigma(\theta, \phi)}{\Delta \Sigma}\right)^{m_{2}} \sin \theta d \theta d \phi
$$

where $\Delta \Sigma=\max \theta, \phi\{\Delta \sigma(\theta, \phi)\}$

Finally, the total probability of failure can be written as:

$$
P_{F 2}=1-\exp \left[-\frac{1}{V_{02}} \int_{V} \frac{\Delta \sum^{m_{2}} J_{m 2}}{\Delta \sum_{02}^{m_{2}}} d V\right]
$$

where

$$
\Delta \Sigma_{02}=\frac{\Delta K_{t h 02}}{\beta \sqrt{\pi a}}
$$

The spatial integration takes into account all possible crack propagation sites and gives better results for multiaxial loading conditions.

The model, presented above, was developed by Pessard et al. [22]. However, it is not well suited to take into account the mean stress effect. An appropriate modification is proposed in the following section.

\subsubsection{Modelling of the mean stress effect for the second damage mechanism}

The mean stress effect is taken into account in the model dedicated to the first fatigue damage mechanism (i.e. meso-plasticity in the material matrix) via the mean value of the normal stress. In order to take into account the mean stress effect, within the model dedicated to the second fatigue damage mechanism (i.e. crack growth from shrinkage pores), the concept of crack closure will be used.

Several authors have been proposed relationships to reflect this effect [30], [31] and [32]. The influence of the load ratio can be observed via its influence on crack propagation rate curves. When the load ratio increases the curves are shifted to the left, or for a given crack propagation rate ( $d a d d M)$ the corresponding value of $\Delta K$ is reduced.

Many authors explain the mean stress effect by the phenomenon of crack closure, initially introduced by Elber [33], whereby a fatigue crack can remain closed during a fraction of the load cycle, close to the minimum load, even when loaded via fully tensile cyclic loads (e.g. $R>0$ ). If it is accepted that a crack can only propagate while it is open, only the corresponding part of the loading cycle effectively contributes to the propagation of the crack. Different mechanisms, resulting in crack closure, have been identified. These include, but are not limited to: plasticity induced crack closure, oxide-induced crack closure, roughness-induced crack closure and viscous fluid-induced crack closure. 
For the majority of materials the value of $\Delta K$ th decreases with an increase in the load ratio [34], [35],[37] and [14]. However, two different types of behaviour can be observed for very high load ratios. For certain materials, the value of $\Delta K$ th achieves a stable value for load ratios going from 0.5 to 0.7 . For others this stabilisation does not occur. Suresh and Ritchie [34] have shown that for SA542 steel the threshold stress intensity value continues to decrease up to a value of $R=0.75$.

Another possible model, that will be used in the following, seems better suited to high load ratios and is very similar to the Klesnil and Lukas [31] approach. It is defined by:

$$
\frac{\Delta K_{t h}}{\Delta K_{t h 0}}=\frac{(1-R)}{(1-\kappa R)}
$$

where $K$ is a material dependant constant.

The left side of Eq. (14) is introduced into the overall expression for the probability of failure for mechanism 2 (Eq. (12)), to account for the mean stress effect on the scale factor. It is important to note that only the form of the relationship $\frac{(1-R)}{(1-\kappa R)}$ is required to apply the model, the scale factor is obtained elsewhere during the identification procedure.

The probability of failure, associated with mechanism 2, can then be given as:

$$
P_{F 2}=1-\exp \left[-\frac{1}{V_{02}} \int_{V} \frac{\Delta \sum^{m_{2}} J_{m 2}}{\Delta \sum_{02}(R)^{m_{2}}} d V\right]
$$

where

$$
\begin{aligned}
\Delta \Sigma_{02}(R) & =\Delta \Sigma_{02}^{\prime} \frac{(1-R)}{(1-\kappa R)} \text { and } J_{m 2} \\
& =\int_{\theta=0}^{\pi} \int_{\phi=0}^{2 \pi}\left(\frac{\Delta \sigma(\theta, \phi)}{\Delta \Sigma}\right)^{m_{2}} \sin \theta d \theta d \phi
\end{aligned}
$$

The next section concerns the predictions of this probabilistic approach with respect to the experimental results obtained for the cast aluminium alloy under investigation.

\section{Application to different microstructural heterogeneities and loading}

\section{modes}

To illustrate the application of the criterion, fatigue data from the literature [6] as well as data from the experimental part of this work (summarised in Table 1) will be used.

- The first part of the criterion, dedicated to the micro-plasticity damage mechanism $\left(P_{F_{1}}\right)$, requires knowledge of three average fatigue limits and the scatter associated with one loading mode (without the presence of porosity). That is:

- the fully reversed torsional fatigue limit, $t_{1}$,

- the fully reversed tensile (or plane bending) fatigue limit, $s_{-1}$,

- a uniaxial fatigue limit with mean stress,

- the data scatter for any loading mode (represented for instance by the standard deviation).

Four parameters must be identified: 
- the biaxiality parameter, $\alpha$,

- the mean stress parameter, $y$,

- the Weibull exponent, $m_{1}$,

- the scale factor,

$$
V_{01} T_{01}^{m_{1}}
$$

- The second part of the criterion, for the mechanisms related to crack propagation and fracture mechanics $\left(P F_{2}\right)$, requires knowledge of two average fatigue limits of the material (with the presence of porosity) and the scatter under one loading mode:

- the fully reversed tensile (or plane bending) fatigue limit, $s_{-1}$,

- a uniaxial fatigue limit with mean stress,

- the data scatter for the tensile loading condition (represented for instance by the standard deviation).

Three parameters must be identified:

- the mean stress (or load ratio) parameter, $\kappa$,

- the Weibull exponent, $m_{2}$,

- the scale factor, $V_{02} T_{02}^{\prime m m_{2}}$.

The parameters $\alpha, y$ and $k$ are identified numerically. The complete procedure is discussed by Huyen et al.[3]. For a material with a HIP treatment, without the presence of porosity, the data obtained by Fan et al. [6]will be used. The mean uniaxial tensile fatigue limit of the material for a load ratio of $R=-$ 1 is equal to $112 \mathrm{MPa}$. The torsional fatigue limit for a load ratio of $R=-1$ is $75 \mathrm{MPa}$. However, the associated standard deviations were not reported. Therefore in the following the Weibull exponent $m_{1}$ is arbitrary set to 20, as Fan et al. [6] specifically highlighted the low scatter in their results, due to the low level of porosity. The influence of this exponent on the criterion predictions will however be investigated.

The fatigue data obtained via testing of the material extracted from the cylinder heads, will be used to identify the Weibull exponent, $m_{2}$, describing the scatter associated with the crack propagation mechanism. The mean uniaxial fatigue strength at $2 \times 10^{6}$ cycles for a load ratio of $R=-1$ is equal to $\bar{S}_{-1}=82 \mathrm{MPa}$. In addition, the standard deviation $\left(\overline{\bar{s}}_{-1}=28 \mathrm{MPa}\right)$ determined via the staircase method, carried out with 20 specimens, is used to calculate the exponent of the Weibull distribution, $m_{2}$. Its identification is done using Eq. (17) and leads to a value of $m_{2}=5$.

$$
\frac{\overline{\bar{s}}_{-1}}{\overline{\bar{s}}_{-1}}=\frac{\sqrt{\Gamma\left(1+\frac{2}{m_{2}}\right)-\Gamma^{2}\left(1+\frac{1}{m_{2}}\right)}}{\Gamma\left(1+\frac{1}{m_{2}}\right)}
$$

\section{$1 \quad 3.1$. Probabilistic Kitagawa type diagrams}

One of the advantages of this modelling framework is the ability to take into account two different fatigue damage mechanisms using a single relationship for different loading modes and mean stress 
values. If the reference volumes related to the two mechanisms are assumed to be the same (i.e. $V_{01}=V_{02}$ ) the probability of failure of the complete structure, $P_{F}$, can be written as:

(18)

$P_{F}=1-\exp \left[-\frac{1}{V_{0}} \int_{V}\left(\frac{\Delta \Sigma^{m_{2}} J_{m 2}}{\Delta \Sigma_{02}(R)^{m_{2}}}+\frac{X_{a}^{m_{1}} I_{m 1}}{T_{01}^{m_{1}}}\right) d V\right]$

Eq. (18) is simply a bimodal Weibull model. For uniaxial tensile loads with a load ratio of $R=-1$, it is possible to determine the evolution of the fatigue limit based on the size of the porosity present in the material. Fig. 3shows that Eq. (18) results in a Kitagawa type diagram and that the predictions are dependent on the two exponents $m_{1}$ and $m_{2}$.
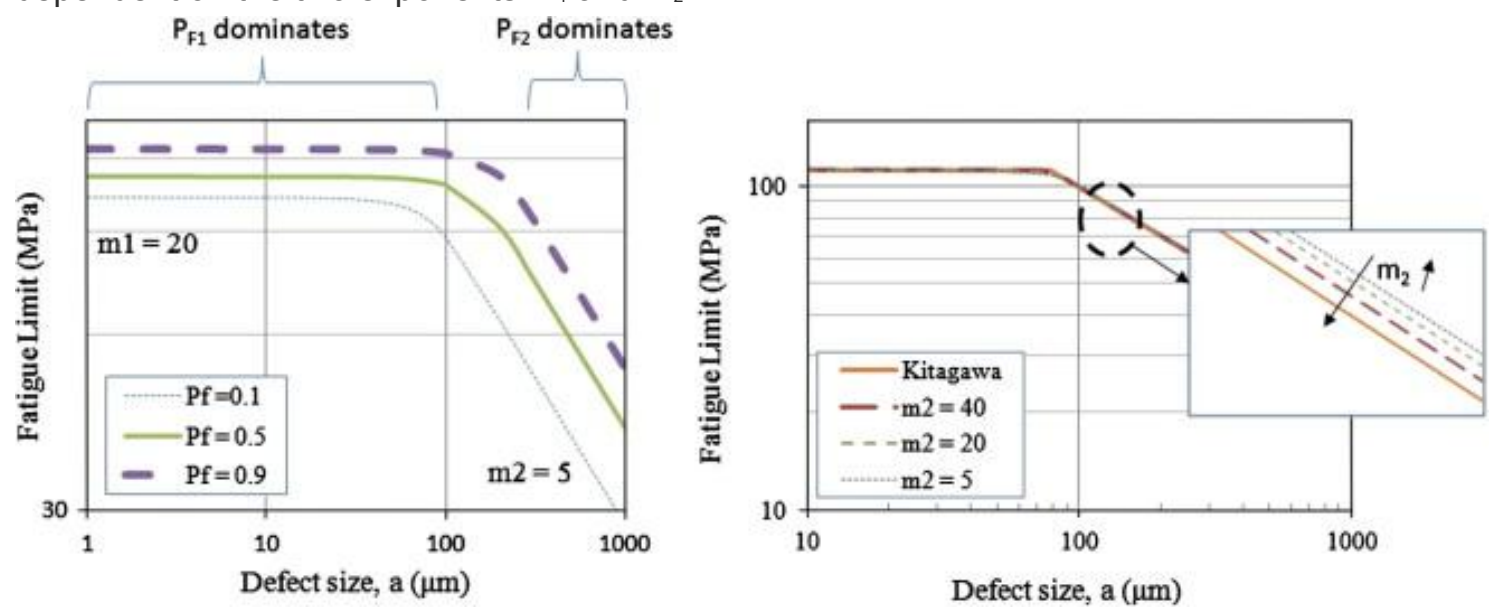

Fig. 3. (a) Kitagawa type diagram for different failure probabilities and (b) the effect of the Weibull exponent, $m_{2}$.

This diagram has been plotted by assuming that the stress intensity threshold range is equal to $\Delta K_{\text {th } 02}=4 \mathrm{MPa} \sqrt{\mathrm{m}}$. This corresponds to the value reported by Couper et al. [36] for a similar material. If the fully reversed bending fatigue limit is used $\left(\Delta \Sigma_{02}=2 \times 83=166 \mathrm{MPa}-\right.$ see Table 1$)$ and it is assumed that the casting defects can be modelled as penny shaped surface cracks (with a crack shape correction factor of $\beta=0.65)$. Then from Eq. $(13)$ it can be seen that this corresponds to a defect size of:

$$
a=\frac{1}{\pi}\left(\frac{\Delta K_{t h 02}}{\beta \Delta \Sigma_{02}}\right)^{2}=\frac{1}{\pi}\left(\frac{4}{0.65 \times 166}\right)^{2}=437 \mu \mathrm{m}
$$

However, it must keep in mind that the defect or crack size used in the model does not correspond to the size of the micro-shrinkage pores present in the material. It includes the size of the shrinkage pores plus the size of non-propagating cracks initiated from the pores. Hence, by definition must be greater than the largest micro-shrinkage pores present in the material (assuming that it is the largest shrinkage pores that control the fatigue behaviour).

A detailed investigation of the micro-shrinkage pore size present in the material using the X-ray tomography technique is presented in the companion paper. In this investigation it was seen that the largest defect found in a scanned volume of $3.546 .5 \mathrm{~mm}^{3}$ was of the order of $230 \mu \mathrm{m}$. It was therefore concluded that the value of $\Delta K_{t h 02}=4 \mathrm{MPa} \sqrt{\mathrm{m}}$ is consistent with the experimental fatigue data. 
For smaller porosity (or defect) sizes, the behaviour is principally controlled by crack initiation from the matrix, while for larger defects, there is a decrease in the fatigue limit with increasing size. Between these two zones there is a transition zone where there exists a competition between the two possible mechanisms.

In order to accurately describe the behaviour of this criterion, the following sections focus firstly on the behaviour of a material characterised by small defects, followed by the behaviour of a material containing large defects.

\subsection{Predictions for small defect size}

In this section, focus is on the zone on the left of the Kitagawa type diagram defined by the relatively horizontal line. The model predictions for combined tension-torsion loads and biaxial tensile loads are analysed and compared with available experimental results.

\subsubsection{Combined in-phase tension-torsion $(R=-1)$}

The predictions of the criterion for combined in-phase tension-torsion loads are shown in Fig. 4. It can be seen that the criterion is in good agreement with the Gough and Pollard empirical criterion [38]. The results for different Weibull exponents and for $50 \%$ probability of failure, show that this parameter has very little effect on the average fatigue behaviour of the material. The only available experimental result, also from the work of Fan et al. [6] for in-phase combined tension-torsion loads with a biaxiality ratio of 0.7 , is also shown. The model gives a prediction very close to the experimental data.

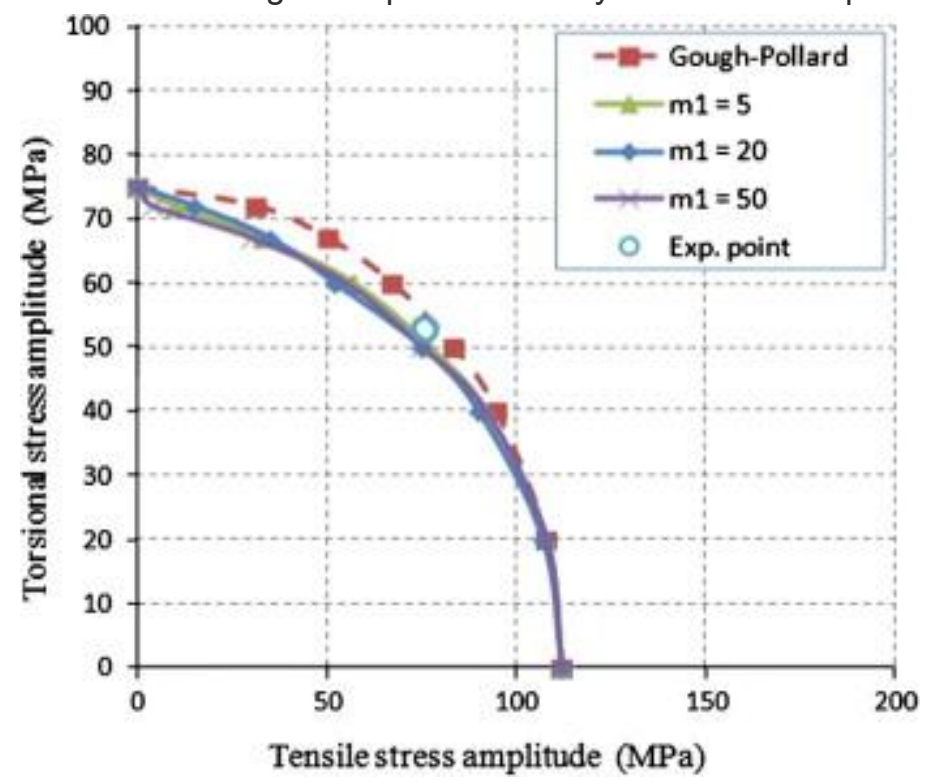

Fig. 4. The criterion predictions for different values of the parameter $m_{1}$ for in-phase combined tension-torsion loads with an $R$-ratio of -1 .

It is also possible to plot the criterion predictions for different failure probabilities, for this loading condition (see Fig. 5). As previously discussed it is not possible to correctly estimate the value of $m_{1}$, however Fig. 5clearly shows the importance of this exponent. Indeed, when $m_{1}$ goes from 20 to 5, the 
difference in the admissible stress between failure probabilities of $10 \%$ and $90 \%$ greatly increases. This is synonymous with greater scatter.
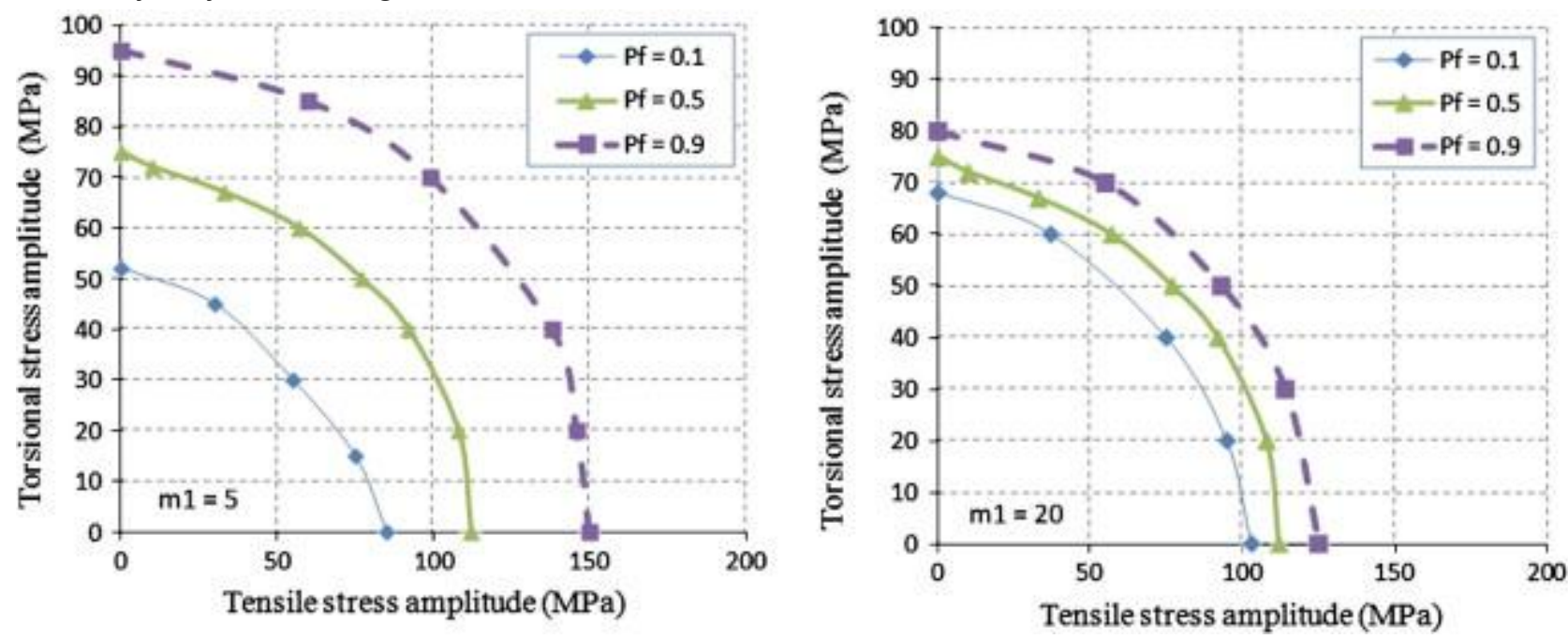

Fig. 5. (a) Predictions of the criterion for different failure probabilities for different Weibull exponents $m_{1}=5$ and 20 for in-phase combined tension-torsion loads with an $R$-ratio of -1 .

\subsubsection{Biaxial tensile loads $(R=-1)$}

The proposed criterion leads to a relatively moderate influence of the biaxiality ratio $\left(k=\frac{\Sigma_{22}}{\Sigma_{11}}\right)_{\text {for }}$ biaxial tensile loading conditions (see Fig. 6). It can be seen that the admissible stress amplitude $\Sigma$ ${ }_{11, a m p}$ does not continuously decrease with increasing biaxiality ratio and that there is even a slight increase for biaxiality ratios close to 0.5 . This increase is a function of the parameter $m_{1}$ and is greater when $m_{1}$ is large. It is very difficult to find experimental results (for biaxial tensile loads) with a load ratio of $R=-1$, especially for this material. However Poncelet et al. [39] have also shown that stress biaxiality is not detrimental compared to a uniaxial loading conditions. Their conclusion was based on a small number of equibiaxial tensile fatigue tests done on an austenitic stainless steel.

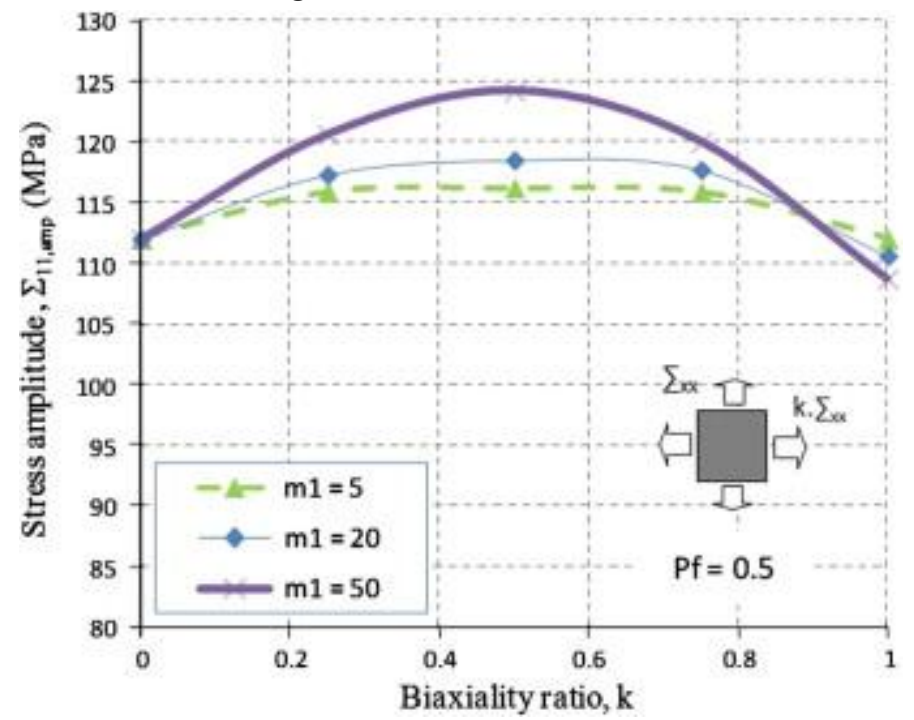

Fig. 6. Effect of the parameter $m_{1}$ on the criterion predictions for biaxial tensile loads $\left(P_{f}=0.5\right)$. 
As per the previous section, it is possible to plot the results of the criterion for different failure probabilities (see Fig. 7). The same remarks concerning the effect of the exponent $m_{1}$ can be made.
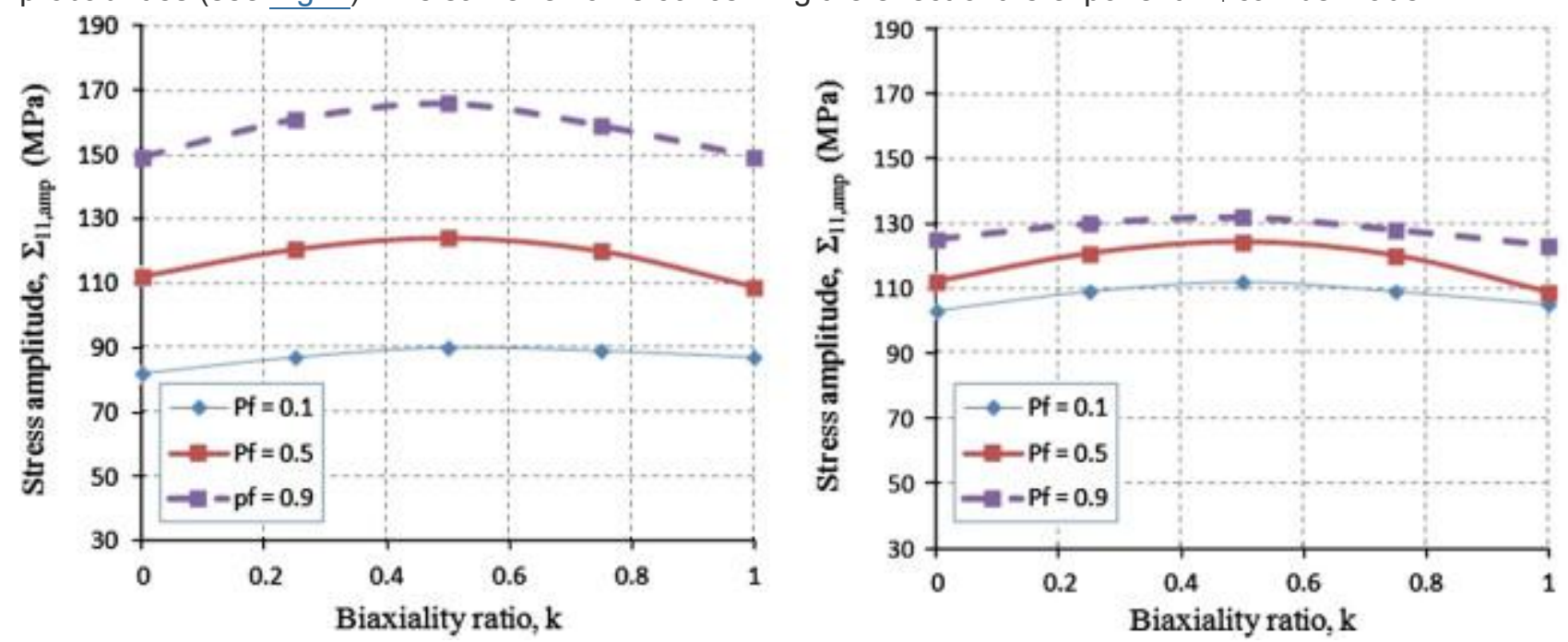

Fig. 7. Results of the criterion for biaxial tensile loads for different failure probabilities and for two different values of the Weibull exponent $\left(m_{1}=5\right.$ and 20$)$.

\subsection{Predictions for large defect size}

This section is devoted to the zone on the right side of the Kitawaga type diagram where the defect size has a large effect on the fatigue strength. In this zone the part of the criterion based on fracture mechanics is dominant. Data from the experimental campaign undertaken by the authors and summarised in Table 1 is used to identify the criterion parameters. It should be noted that this material was sand cast and is characterised by a relatively large average porosity size. The material has a uniaxial tensile fatigue limit $(R=-1)$ at $2 \times 10^{6}$ cycle of $s_{-1}=83 \mathrm{MPa}$ and a fully reversed torsional fatigue limit at $2 \times 10^{6}$ cycle of $t_{-1}=92 \mathrm{MPa}$. The Weibull exponent controlling the scatter associated with the crack propagation mechanism was determined to be $m_{2}=5$ using this data.

In the following the predictions for torsional loads and in-phase biaxial tensile loads are analyzed and compared with the available experimental results.

\subsubsection{Biaxial tensile loads $(R=-1)$}

Fig. 8 shows that the average predictions of the criterion are not greatly influenced by the biaxiality ratio when the Weibull exponent $m_{2}$ is large. For the case where the value of $m_{2}$ is small, corresponding to a high degree of scatter, there is a drop in the admissible stress amplitude with increasing biaxiality ratio. This differs from the predictions for a defect-free material where there is an increase in the admissible stress for the biaxiality ratio of 0.5 . It is very difficult to validate this behaviour because no data for this loading condition (i.e. $R=-1$ ) and this type of material could be found in literature. However, for equibiaxial loads with $R=0.1$, the experimental results do not show a strong effect of the biaxial ratio. 

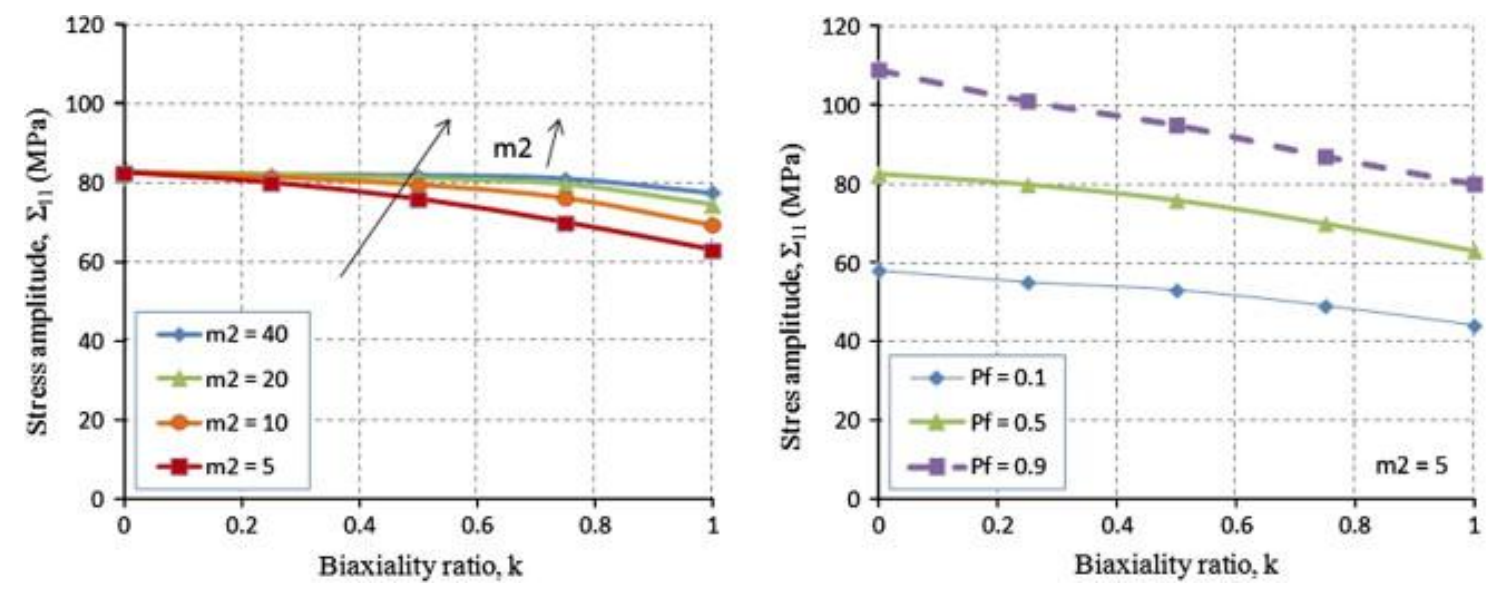

Fig. 8. (a) Criterion prediction as a function of the biaxiality ratio for different Weibull parameters and (b) for several failure probabilities for a Weibull exponent of $m_{2}=5$.

As per the previous section, it is possible to represent the criterion predictions for different failure probability (see Fig. 8b). This figure is for a Weibull exponent of $m_{2}=5$, which is the experimentally determined value and corresponds to a high degree of scatter. Consequently, it can be seen that there is a large difference between the admissible stress amplitude for failure probabilities of $90 \%$ and $10 \%$.

\subsubsection{Uniaxial loads (in plane bending)}

The objective of this section is to consider the mean stress effect in terms of plane bending for the sand gravity cast aluminium alloy (AISi7Cu05Mg03). The predictions obtained are plotted in Fig. 9. This figure shows the admissible stress amplitude as a function of the mean stress. It can be seen that the predictions are in very good agreement with the experimental results. The dependence on the $R$ ratio is such that the mean stress effect is not affected by the Weibull exponent $m_{2}$ (see Eqs. (15) and (16)).

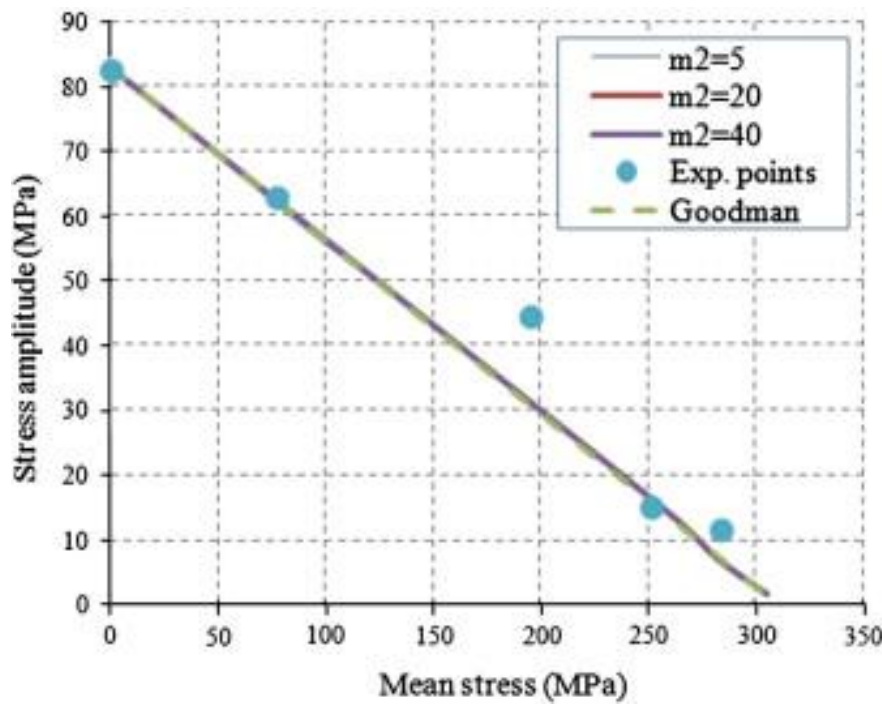

Fig. 9. Comparison between the predictions of the criterion (with different value of $m_{2}$ ) and the experimental data for the cast aluminium alloy in the form of a Haigh diagram. The Goodman criterion is also shown. 


\subsubsection{Fully reversed torsional loads}

It is important to note that for the model describing crack initiation in the material matrix (i.e. for small defects), the fatigue limit in torsion was necessary to identify the criterion parameters. This is not the case here. The curve shown in Fig. 10 shows the change in the predicted torsional fatigue limit as a function of the parameter $m_{2}$.

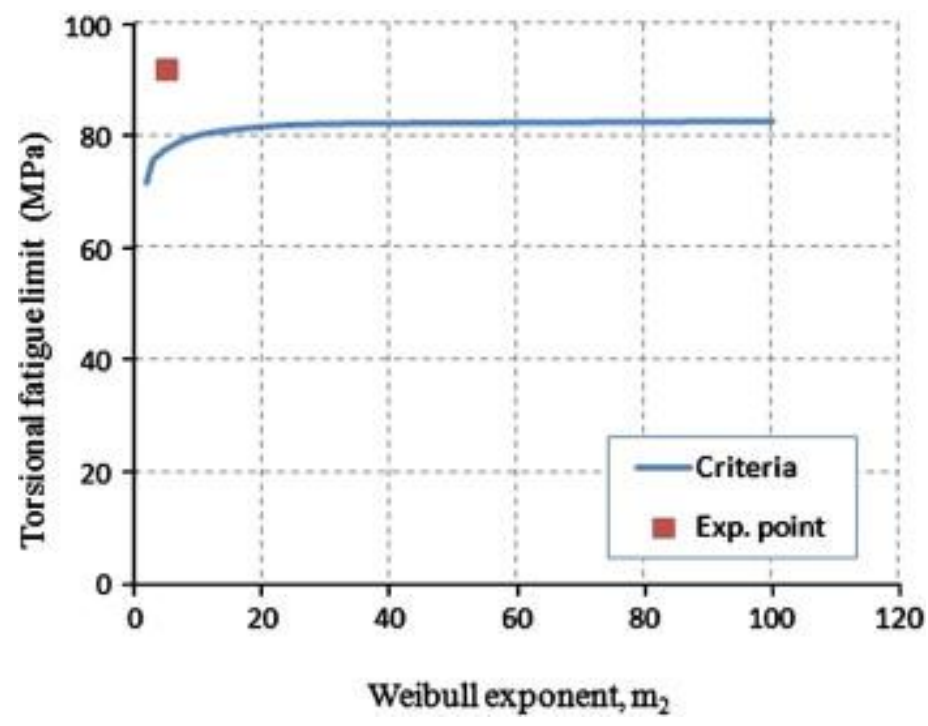

Fig. 10. The predicted torsional fatigue limit as a function of the parameter $m_{2}$.

It can be seen that the predicted torsional fatigue limit increases with increasing $m_{2}$, and tends to the plane bending fatigue limit of the material (i.e. $f_{-1}=83 \mathrm{MPa}$ ). Thus, according to the criterion, a material with a high level of scatter leads to a lower torsional fatigue limit than a material with less scatter. This finding must be qualified by noting that the difference between the plane bending fatigue limits and the torsional limit is very low (approx. $10 \mathrm{MPa}$ ).

Surprisingly, the experimental results show a fatigue limit in torsion ( $\left.t_{-1}=92 \mathrm{MPa}\right)$ which is higher than in plane bending and therefore higher than the value predicted by the criterion. This error is acceptable, however a possible explanation could be due to a volume effect. That is, the volume of highly stressed material in the torsional specimens was lower than for the specimens loaded in plane bending.

For other materials with defects (or porosity) such as nodular cast iron (which also has high scatter in terms of fatigue), Nadot and Denier [40] showed that the uniaxial tensile fatigue limit and the torsional fatigue limit are very similar (approx. $225 \mathrm{MPa}$ ). This confirms the overall good performance of the proposed model for the torsional loading of a material with defects.

\subsubsection{Biaxial tensile loads}

In a previous section it was observed that for a load ratio of $R=-1$, a decrease of the exponent $m_{2}$ tended to accentuate the damaging effect of the biaxiality (see Fig. 8a). Fig. 11 shows the effect of the mean stress for an equibiaxial in-phase loading mode, for different values of $m_{2}$. 


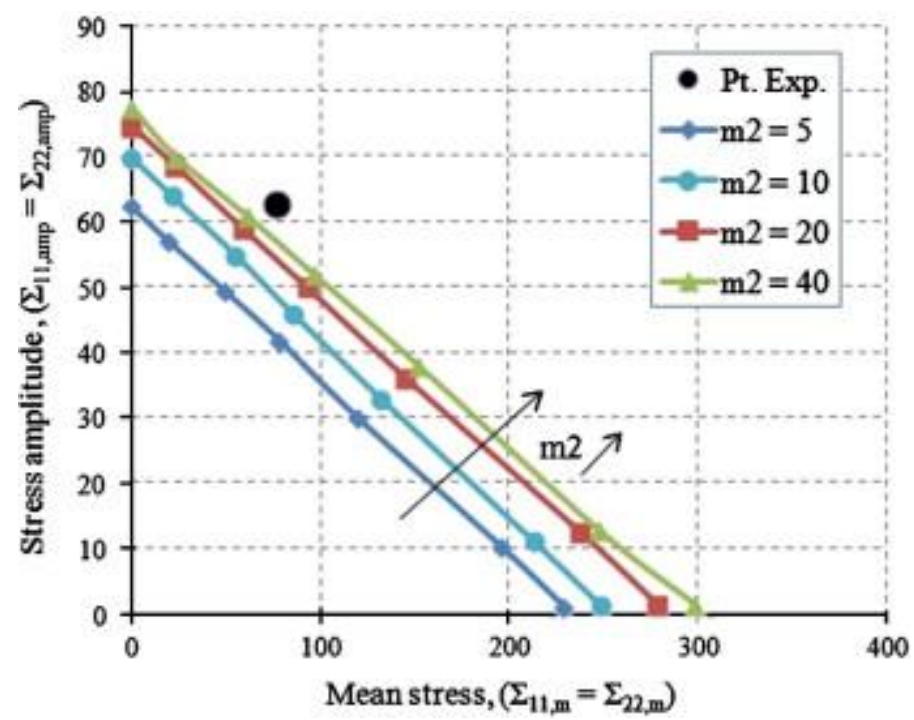

Fig. 11. Haigh diagram adapted to equibiaxial in-phase tensile loads for different Weibull exponents for the cast aluminium alloy.

From this figure it can be seen that the criterion predictions appear conservative compared to the one experimental data point available for a load ratio of $R=0.1$. The predictions for different values of the Weibull exponent $m_{2}$ are shown as the experimental identification of $m_{2}$ was only done for a load ratio of $R=-1$. The number of tests with a mean stress was not sufficient (i.e. 10 test per $R$-ratio) to accurately estimate the Weibull exponent associated with the corresponding scatter. However, it is observed that a high value of $m_{2}$ is required to get the best predictions.

\subsection{Critical analysis of the proposed criterion}

The principal objectives for the development of this probabilistic fatigue model were to correctly take into account the effect of various microstructural heterogeneities and to accurately reproduce the experimental trends observed for varied multiaxial loading conditions.

In order to compare the predictions from the proposed criterion with the experimental data for the totality of the loading conditions investigated the Dang Van diagram is used. The Dang Van criterion is based on a two scale approach [1], [19] and [20]. The two mechanical parameters used are the mesoscopic resolved shear stress obtained for the elastic shakedown state $r$ and the hydrostatic stress $\Sigma H$. The criterion is expressed as a linear combination of these two parameters:

(20) $\quad T+\alpha \Sigma H \leqslant \beta$

where $\tau$ and $\Sigma H$ are both functions of time. In the criterion plane, the load path associated with a given loading condition changes with the mean stress level and the stress state. All the load conditions discussed in this work lead to proportional loading paths, however in Fig. 12, only the most critical points of the paths are shown. The dotted line on the diagram corresponds to the Dang Van Criterion, identified using the fully reversed experimentally determined torsional and plane bending fatigue limits. It can be seen that the predictions of the proposed criterion (i.e. the non-solid data points) are in general, closer to the experimental data (i.e. the solid data points) compared to the Dang Van 
criterion. Fig. 12 highlights the fact that the Dang Van criterion has difficulty predicting the fatigue behaviour of this type of material.

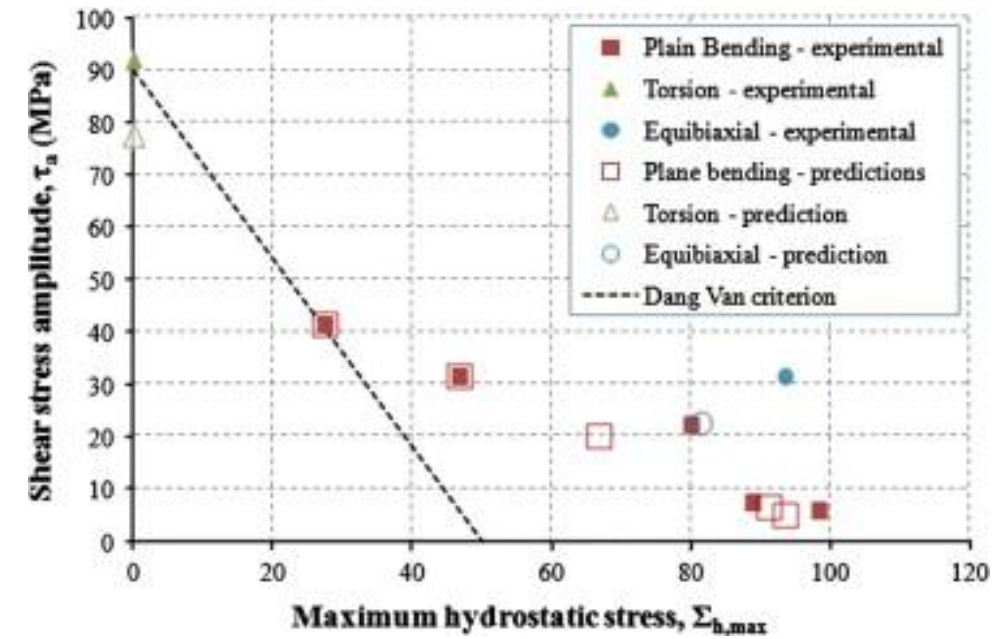

Fig. 12. Dang Van diagram, showing the predictions of the proposed criterion and the corresponding experimental data for the cast aluminium alloy AISi7Cu05Mg03-T7.

The predictions of the proposed criterion are close to the experimental results for the uniaxial load conditions with different mean values and lead to conservative results for the multiaxial loading conditions. That is, the predictions are below the experimental data points.

\section{Discussion and conclusion}

The principal objective of this work was to develop a probabilistic high cycle fatigue model adapted to Al-Si cast alloys, which is able to take into account the different microstructural heterogeneities present in the material and has the capacity to reproduce the experimentally observed tendencies for very different multiaxial loading conditions.

Based on a large number of data taken from the literature and the vast experimental campaign undertaken by the authors (See Footnote 1), it has been concluded that two coexisting fatigue damage mechanisms occur in this material. When the influence of micro-shrinkage pores is reduced, by a HIP treatment for example, the multiaxial fatigue behaviour is controlled via meso-plasticity occurring in the material matrix. This is very different to the damage mechanism observed with a typical gravity sand cast material, for which the dominate crack leading to final fatigue typically occurs at a micro-shrinkage pore. It is important to note that, even in this case, the first damage mechanism is still present, but rarely leads to failure.

In order to take into account both of these damage mechanisms, a probabilistic approach using the weakest link concept is employed to model the competition between the two mechanisms. This approach leads naturally to a probabilistic Kitagawa type diagram, which in this case explains the relationship between the fatigue behaviour of the material and the different casting processes or postcasting treatments (i.e. gravity casting and HIP). 
A major advantage of this modelling framework concerns the question of "small crack propagation". It is generally accepted that linear elastic fracture mechanics is not suitable to predict the propagation behaviour of small cracks. However, in the modelling framework presented here this is not an issue. If the second damage mechanism (modelled using a LEFM approach) is dominate the problem is by definition one of "long crack propagation" and will be situated on the right-hand side of the Kitagawa diagram.

It is shown that the proposed model is capable of reproducing the experimentally observed tendencies, with respect to both the mean stress effect and the loading mode (torsion, uniaxial tension and equibiaxial tension). It is shown that the effect of a biaxial stress state is not as detrimental as the predictions of the Dang Van criterion, which uses the hydrostatic stress.

\section{Acknowledgments}

This work was undertaken in partnership with PSA Peugeot Citroën and was financially supported by the French region Pays de la Loire.

\section{References}

[1] K. Dang Van

Sur la résistance à la fatigue des métaux

Sci Tech Armement, 47 (1973)

[2] F. Morel, N. Huyen

Plasticity and damage heterogeneity in fatigue

Theor Appl Fract Mech, 49 (1) (2008), pp. 98-127

[3] N. Huyen, L. Flacelière, F. Morel

A critical plane fatigue model with coupled meso-plasticity and damage

Fatigue Fract Eng Mater Struct, 31 (1) (2008), pp. 12-28

[4]Y.X. Gao, J.Z. Yi, P.D. Lee, T.C. Lindley

A micro cell model of the effect of the microstructure and defects on fatigue resistance in cast aluminum alloys

Acta Mater, 52 (2004), pp. 5435-5449

[5]D.L. Mc Dowell, K. Gall, M.F. Horstemeyer, J. Fan

Microstructure-based fatigue modeling of cast A356-T6 alloy

Eng Fract Mech, 70 (2003), pp. 49-80

[6]J. Fan, D.L. Mc Dowell, M.F. Horstemeyer, K. Gall

Cyclic plasticity at pores and inclusions in cast Al-Si alloys

Eng Fract Mech, 70 (2003), pp. 1281-1302 
[7]B. Zhang, W. Chen, D.R. Poirier

Effect of solidification cooling rate on the fatigue life of A356.2-T6 cast aluminium alloy

Fatigue Fract Eng Mater Struct, 23 (5) (2000), pp. 417-423

[8]X. Zhu, J.Z. Yi, J.W. Jones, J.E. Allison

A probabilistic model of fatigue strength controlled by porosity population in a 319-type cast aluminum alloy: Part I. Model development

Metall Mater Trans A, 8 (5) (2007), pp. 1111-1122

[9]J.Y. Buffière, S. Savelli, P.H. Jouneau, E. Maire, R. Fougères

Experimental study of porosity and its relation to fatigue mechanisms of model Al-Si7-Mg0.3 cast AL alloy

Mater Sci Eng A, 316 (2001), pp. 115-126

[10]Q.G. Wang, D. Apelian, D. A Lados

Fatigue behavior of A356-T6 aluminum cast alloys. Part I. Effect of casting defects

J Light Met, 1 (1) (2001), pp. 73-84

[11]Q.G. Wang, D. Apelian, D.A. Lados

Fatigue behavior of A356-T6 aluminum cast alloys. Part II: Effect of microstructural constituents

J Light Met, 1 (2001), pp. 85-97

[12]M. Brochu, Y. Verreman, F. Ajersch, D. Bouchard

High cycle fatigue strength of permanent mold and rheocast aluminium 357 alloy

Int J Fatigue, 32 (8) (2010), pp. 1233-1242

[13]M.J. Caton, J.W. Jones, J.E. Allison

The influence of heat treatment and solidification time on the behavior of small fatigue cracks in a cast aluminum alloy

Mater Sci Eng A, 314 (1998), pp. 81-85

[14]B.E. Powell, T.V. Duggan

Predicting the onset of high cycle fatigue damage: an engineering application for long crack fatigue threshold data

Int J Fatigue, 8 (4) (1986), pp. 187-194

[15]B. Skallerud, T. Iveland, G. Harkegard

Fatigue life assessment of aluminum alloys with casting defects

Eng Fract Mech, 44 (6) (1993), pp. 857-874

[16]J. Linder, M. Axelsson, H. Nilsson

The influence of porosity on the fatigue life for sand and permanent mould cast aluminum 
Int J Fatigue, 28 (2006), pp. 1752-1758

[17]H. Mayer, M. Papakyriacou, B. Zettl, S.E. Stanzl-Tschegg

Influence of porosity on the fatigue limit of die cast magnesium and aluminium alloys

Int J Fatigue, 25 (2003), pp. 245-256

[18]J.Z. Yi, P.D. Lee, T.C. Lindley, T. Fukui

Statistical modeling of microstructure and defect population effects on the fatigue performance of cast A356-T6 automotive components

Mater Sci Eng A, 432 (2006), p. 5968

[19]E. Charkaluk, A. Constantinescu, H. Matournam, K. Dang Van

Revisiting the Dang Van criterion

Proc Eng, 1 (1) (2009), pp. 143-146

[20]K. Dang Van

Macromicro approach in high-cycle multiaxial fatigue

,in: D.L. McDowell, R. Ellis (Eds.), A dvances in multiaxial fatigue, ASTM STP, vol. 1191, ASTM, Philadelphia, PA (1993), p. 12030

[21]Papadopoulos IV. Fatigue limit of metals under multiaxial stress conditions: the microscopic approach.

ISEI/IE 2464/93. Commission of the European Communities Joint Research Center; 1993.

[22]E. Pessard, F. Morel, A. Morel

The anisotropic fatigue behavior of forged steel

Adv Eng Mater, 11 (2009), pp. 732-735

[23]E. Pessard, F. Morel, A. Morel, D. Bellett

Modelling the role of non-metallic inclusions on the anisotropic fatigue behaviour of forged steel

Int J Fatigue, 33 (4) (2011), pp. 568-577

[24]E. Pessard, F. Morel, C. Verdu, L. Flacelière, G. Baudry

Microstructural heterogeneities and fatigue anisotropy of forged steels

Mater Sci Eng A, 529 (1) (2011), pp. 289-299

[25]H. Yaacoub Agha, A.-S. Beranger, R. Billardon, F. Hild

Statistical damage tolerance for cast iron under fatigue loadings

Stud Appl Mech, 45 (1997), pp. 415-424

[26]l. Chantier, V. Bobet, R. Billardon, F. Hild

A probabilistic approach to predict the very high cycle fatigue behaviour of spheroidal graphite cast iron structures

Fatigue Fract Eng Mater Struct, 23 (2000), p. 173

[27]L. Flacelière, F. Morel 
Probabilistic approach in multiaxial high cycle fatigue: volume and surface effects

Fatigue Fract Eng Mater Struct, 27 (2004), pp. 1123-1135

[28]W. Weibull

A statistical theory of the strength of materials

Roy Swed Inst Eng Res Rep, 151 (1939)

[29]W. Weibull

A statistical distribution function of wide applicability

ASME J Appl Mech, 18 (1951), pp. 293-297

[30]R. Schmidt, P.C. Paris

Threshold for fatigue crack propagation and the effects of load ratio and freqeuncy

ASTM STP, 536 (1973), pp. 79-94

[31]M. Klesnil, P. Lukas

Effect of stress cycle asymmetry on fatigue crack growth

Mater Sci Eng, 9 (1972), pp. 231-240

[32]D. Kujawski

A fatigue crack driving force parameter with load ratio effects

Int J Fatigue, 23 (SUPPL 1) (2001), pp. S236-S246

[33]W. Elber

Fatigue crack closure under cyclic tension

Eng Fract Mech, 2 (1970), pp. 37-45

[34]S. Suresh, R.O. Ritchie

On the influence of environment on the load ratio dependence of fatigue thresholds in pressure vessel steel

Eng Fract Mech, 18 (4) (1983), pp. 785-800

[35]S. Kawai

The effect of the stress ratio on fatigue crack growth in a $3 \% \mathrm{NaCl}$ solution

Eng Fract Mech, 16 (6) (1982), pp. 857-870

[36]M.J. Couper, A.E. Neeson, J.R. Griffith

Casting defects and the fatigue behavior of an aluminum casting alloy

Fatigue Fract Eng Mater Struct, 13 (3) (1990), pp. 213-217

[37]S.-L. Chen, Y. Zuo, Y.A. Chang

A thermodynamic description for the ternary $\mathrm{Al}-\mathrm{Mg}-\mathrm{Cu}$ system 
[38]H.J. Gough, H.V. Pollard

The strength of metals under combined alternating stresses

Proc Inst Mech Eng (London), 131 (1935), p. 1103

[39]M. Poncelet, G. Barbier, B. Raka, L. Vincent, R. Desmorat

Etude de lendomagement dun acier inoxydable austenitique par fatigue multiaxiale grand nombre de cycles

J Printemps SF2M (2009)

[40]Y. Nadot, V. Denier

Fatigue failure of suspension arm: experimental analysis and multiaxial criterion

Eng Fail Anal, 11 (2004), pp. 485-499 